\title{
Diagnostic Yield of Fiber Optic Bronchoscopy and CECT Thorax in Patients of Haemoptysis with Normal Chest X-Ray
}

\author{
Agarwala $A^{1}$, Basuthakur $S^{2}$, Shamim $S^{3}$, Saha $K^{4}$, Bhattacharya $S^{5}$, Sengupta $A^{6}$ \\ ${ }^{1}$ Dr Abinash Agarwala, R.M.O. cum C.T. Chest ,Medinipore Medical College \& Hospital, West Bengal, ${ }^{2}$ Dr. Sumitra \\ Basuthakur, Professor \& H.O.D, Chest \& Respiratory Medicine, Calcutta Medical College, Kolkata, ${ }^{3}$ Dr. Shelley \\ Shamim, Associate Professor, Calcutta National Medical College \& Hospital, Kolkata, ${ }^{4}$ Dr. Kaushik Saha, Assistant \\ Professor, B.M.C \& H,West Bengal, ${ }^{5}$ Dr. Sujit Bhattacharya Assistant Professor, N.R.S.M.C.\& H, Kolkata, ${ }^{6}$ Dr. Amitabha \\ Sengupta, Associate Professor, , N.R.S.M.C.\&H, Kolkata, India
}

\begin{abstract}
Introduction: Contrast enhanced computed tomography (CECT) thorax \& Fibre Optic Bronchoscopy (FOB) are main investigations in patients of hemoptysis with normal chest X-ray. But there are limited data on their diagnostic yield especially from South East Asia. Methods: An observational study on 60 patients with hemoptysis with normal chest X ray was conducted from April 2012 to April 2014. CECT thorax and FOB were done in all of them. Results: Out of 60 patients $38(63.3 \%)$ were male with even age distribution. Yield of CECT was 40\% (24 patients) and main diagnosis were bronchiectesis $(25 \%)$ and tuberculosis $(11.6 \%)$. Diagnostic yield of FOB was $47 \%$ (28 patients) with predominant diagnosis of tuberculosis (18.33\%), bronchitis (18.33\%) and bronchogenic carcinoma (6.66\%). Overall diagnostic yield was $76.6 \%$ (46 cases). Bronchogenic carcinoma cases were all male smokers and 3 of them were more than 40 years old. Conclusion: CECT thorax and FOB are complimentary to each other in evaluation of hemoptysis with normal chest $\mathrm{x}$ ray. Bronchogenic carcinoma and tuberculosis cases require specific treatment and they were diagnosed in confirm way only by FOB. So, FOB have advantage over CT scan, especially among patients with increased risk of bronchogenic carcinoma (male-smokers with age $>40$ years).
\end{abstract}

Keywords: Computed Tomography Thorax, Bronchoscopy, Hemoptysis, Radiography, Thoracic

\section{Introduction}

A chest radiograph (CXR) is essential for the diagnostic evaluation of haemoptysis. However, about $20-30 \%$ of patients with haemoptysis show CXR which is normal or non-localizing [1].

Some of the lung parenchymal lesion is obscured by ribs, diaphragm and mediastinum. Therefore abnormalities behind these structures may not be visible on plain chest radiographs [2]. Also small intrabronchial lesion may not be seen in simple $\mathrm{x}$ ray. In these conditions we need further tests like CT scan and Fiber Optic Bronchoscopy (FOB).

F.O.B allows direct visual examination and collection of histological samples from the proximal endobronchial tree [3]. However, F.O.B is not useful in detecting lesions in distal airways and lung parenchyma. CT-

Manuscript received: $1^{\text {st }}$ Dec 2014

Reviewed: $16^{\text {th }}$ Dec 2014

Author Corrected: $4^{\text {th }}$ Jan 2015

Accepted for Publication: $11^{\text {th }}$ Jan 2015
Scan of thorax detects both endobronchial and parenchymal abnormalities, but does not allow histological diagnosis [4].

In this background whether the clinician should choose FOB before a CT scan or vice versa for evaluation of patients with haemoptysis and normal CXR is still debatable. Especially data in this regard is very limited from south East Asia. So this study was done to evaluate diagnostic yield of both CT scan and FOB in patients with hemoptysis with normal chest $X$ ray, so that we have an idea of the efficacy of FOB first or CT first approach in the diagnostic algorithm. Also it was tried to evaluate total number of missed significant diagnosis if only FOB is done or if only CT is done.

\section{Materials and Method}

A prospective observational study was carried out from April'2012 to April'2014. Ethical committee clearance of our institute was taken. All the patient who came to out patient department with hemoptysis during that 
period were included and after applying inclusion and exclusion criteria, 60 patients were selected for this study.

Inclusion criteria were (i) 15-65 years age of both genders with one or more episodes of hemoptysis and normal chest X-ray, (ii) Normal bleeding time, clotting time and prothrombin time, (iii) Negative result of sputum for AFB test done from R.N.T.C.P. microscopy clinic and (iv) willingness of patient to give informed consent.

Exclusion criteria were i) Presence of cardiovascular diseases like known ischemic heart disease or past history of myocardial infarction, ii) Pregnancy (as CT can't be done in these patients) and iii) Persistent massive hemoptysis. In every patient platelet count, bleeding time, coagulation time, prothrombin time and sputum for A.F.B for two times were done.

FOB was done in all of these patients through transnasal route. Bronchoscope used was Pentax adult bronchoscope, model no FB-15P. After proper visualization of the tracheobronchial tree to exclude endobronchial growth, mucosal irregularities, ulceration or external compression, BAL fluid was taken from every patient. The BAL fluid was sent for following investigations: 1) Cell type, 2) Gram stain, Ziehl Neelsen (Z.N.) stain for AFB, 3) Papanicolaou stain for malignant cells and 4) BACTEC culture for mycobacterium tuberculosis. If there was any visible endobronchial growth, mucosal irregularities or ulceration, biopsy was taken and sent for histopathological examination. Bronchitis was diagnosed by bronchoscopic evidence of inflammation in the wall that is redness and edema involving multiple segments with mucosal biopsy report suggesting non specific bronchitis.

CECT scan of thorax was also done to every patient after control of hemoptysis. The diagnostic yield of F.O.B. and CECT thorax was calculated, Percentage of idiopathic cases of hemoptysis was determined. Numbers of significant missed diagnosis if only FOB is done or if only CT is done were evaluated.

\section{Results and Analysis}

A total 60 patients were included in this study and they were distributed in all the age groups. In both $\leq 40 \mathrm{yrs}$ and $>40$ yrs of age there were equal $(n=30)$ number of patients. Of the 60 cases, 38(63.33\%) were males and $22(36.66 \%)$ were females. Females were mainly in $\leq 40$ yrs age group. $91 \%$ females were in this age range. Whereas in $>40$ yrs age group 28(93.3\%) were males (table 1).

Table-1: Distribution of the patients according to age, sex and smoking history.

\begin{tabular}{|c|c|c|}
\hline Age (Years) $n=60$ & \multicolumn{2}{|l|}{ Percentage (\%) } \\
\hline $20-30$ yrs & \multicolumn{2}{|l|}{$20(33.3 \%)$} \\
\hline $31-40 \mathrm{yrs}$ & \multicolumn{2}{|l|}{$10(16.6 \%)$} \\
\hline $41-50$ yrs & \multicolumn{2}{|l|}{$17(28.3 \%)$} \\
\hline $51-60$ yrs. & \multicolumn{2}{|l|}{$10(16.6 \%)$} \\
\hline$>60$ yrs. & \multicolumn{2}{|l|}{$03(05.0 \%)$} \\
\hline $\begin{array}{l}\text { Sex distribution } \\
N=60\end{array}$ & $\begin{array}{l}\text { Male } \\
\text { Female }\end{array}$ & $\begin{array}{l}38(63.3 \%) \\
22(36.6)\end{array}$ \\
\hline$\leq 40$ Yrs age $(n=30)$ & $\begin{array}{l}\text { Male } \\
\text { Female }\end{array}$ & $\begin{array}{l}10(33.3 \%) \\
20(66.6 \%)\end{array}$ \\
\hline$>40$ yrs age $(n=30)$ & $\begin{array}{l}\text { Male } \\
\text { Female }\end{array}$ & $\begin{array}{l}28(93.3 \%) \\
2(0.06 \%)\end{array}$ \\
\hline Smoking history $(\mathrm{n}=60)$ & $\begin{array}{l}\text { smoker } \\
\text { nonsmoker }\end{array}$ & $\begin{array}{l}28(46.6 \%) \\
32(53.3 \%)\end{array}$ \\
\hline Male $(n=38)$ & $\begin{array}{l}\text { smoker } \\
\text { nonsmoker }\end{array}$ & $\begin{array}{l}28(73.6 \%) \\
10(26.3 \%)\end{array}$ \\
\hline Female $(n=22)$ & $\begin{array}{l}\text { smoker } \\
\text { nonsmoker }\end{array}$ & $\begin{array}{l}\text { Nil } \\
22(100 \%)\end{array}$ \\
\hline Age $\leq 40$ yrs $(n=30)$ & $\begin{array}{l}\text { smoker } \\
\text { nonsmoker }\end{array}$ & $\begin{array}{l}6(20 \%) \\
24(80 \%)\end{array}$ \\
\hline Age $>40$ yrs $(n=30)$ & $\begin{array}{l}\text { smoker } \\
\text { nonsmoker }\end{array}$ & $\begin{array}{l}22(73.3 \%) \\
8(26.6 \%)\end{array}$ \\
\hline
\end{tabular}


History of smoking was present in $28(46.66 \%)$ patients. All the smokers in this study were male. Most of the smokers were in age group more than 40 yrs (total 22out of 28) ( table 1).

Table-2: Yield of C.T. Scan in this study $(n=60)$

\begin{tabular}{|l|l|}
\hline Disease & Number \\
\hline Bronchiectasis & $15(25 \%)$ \\
\hline Small consolidation/nodule, suspected tubercular lesions & $7(11.66 \%)$ \\
\hline Other cause & $02(3.33 \%)$ \\
\hline Total & $24(40 \%)$ \\
\hline
\end{tabular}

The diagnosis was made by CECT in $24(40 \%)$ cases \& by F.O.B in $28(47 \%)$ cases. In CECT, we diagnosed bronchiectasis in $15(25 \%)$ cases. In 7 (11.6\%) cases CT revealed small consolidation with nodules with often tree in bud appearance suggesting suspected tubercular lesions (table 2). In 6 out of these 7 cases tuberculosis was confirmed by BACTEC culture by FOB.

Table-3: Yield of F.O.B in this study $(n=60)$

\begin{tabular}{|l|l|}
\hline Disease & number \\
\hline Tuberculosis & $11(18.33 \%)$ \\
\hline Bronchitis & $11(18.33 \%)$ \\
\hline Bronchogenic CA & $04(6.66 \%)$ \\
\hline Others & $02(3.33 \%)$ \\
\hline Total & $28(47 \%)$ \\
\hline
\end{tabular}

In FOB, we diagnosed tuberculosis in $11(18.33 \%)$ cases in which 6 had some contributory finding in CT. Bronchitis in $11(18.33 \%$ ) cases and bronchogenic carcinoma in $4(6.66 \%)$ cases were the other prominent diagnosis in FOB (table 3 ).

We diagnosed one case of A-V malformation and one sequestration of lung by CECT Thorax and two cases of bronchial adenoma by F.O.B. These cases are included in 'others" cases category. If only FOB was done, than we missed 18(39.1\% of total cases) cases ( 15 bronchiectesis, 1 tuberculosis , 2 others) to diagnosed.

If only CT was done, in 22 cases (47.8\% of total diagnosis) (5 tuberculosis, 11 bronchitis, 4 bronchogenic ca, others 2 ) diagnosis would have been missed. Also in 6 patients of tuberculosis diagnosis would have been only suspected not confirmed (As diagnoses of those cases were confirmed by positive BACTEC culture from BAL by FOB).

Diagnosis like tuberculosis and bronchogenic ca which requires specific treatment were most of the time diagnosed (15 out of 16 cases) by FOB.

Altogether in 46(76.6\%) cases we had at least some kind of diagnosis by these two methods. In remaining 14 (23.4\%) cases diagnosis remained to be idiopathic. Distribution of different etiology is shown in fig 2.

Fig-1: Etiological yield in both procedure and relation to smoking.

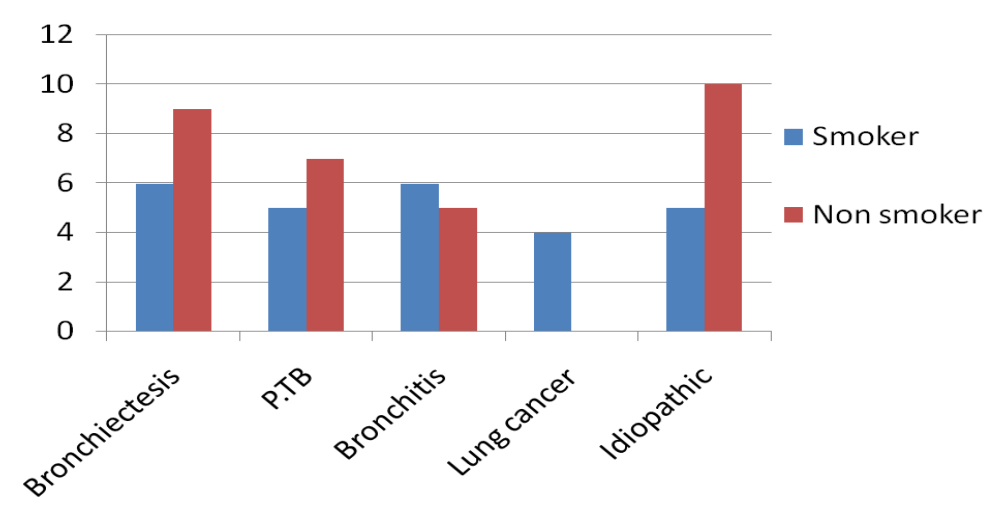


All the 4 patients of bronchogenic carcinoma were smokers. The smoker, nonsmoker ratios in tuberculosis, bronchiectesis and bronchitis were almost equal in our study (fig 1).

Fig- 2: Relation of age with different etiological diagnosis

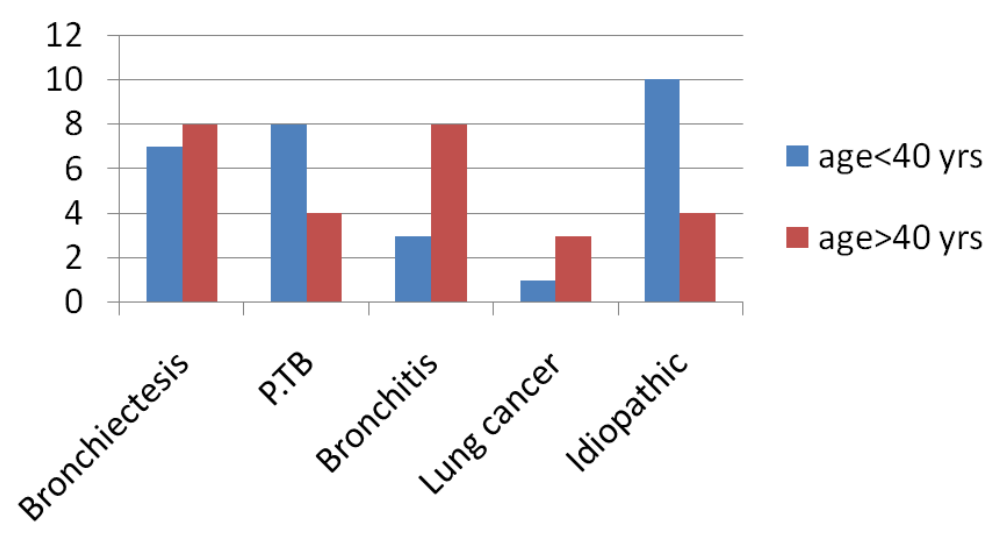

Also bronchogenic carcinoma cases were all male and most of them had age of $>40 \mathrm{yrs}$. Male female ratio in other causes of hemoptysis is similar to the male female ratio of our study population. Most of the PTB (66.7\% of PTB) and idiopathic $(71.4 \%$ of them) cases were from younger $(<40 \mathrm{yrs})$ age groups where as most of the bronchitis $(72.7 \%$ of them $)$ cases were from older ( $>40 y r s)$ age group. $(p=.0283$, Chi Square Test without Yates correction)

\section{Discussion}

In a patient with hemoptysis with normal chest $\mathrm{X}$ ray, we have two options for further evaluation either CT scan thorax or FOB. Although both may required for diagnosis, but in a resource limited country like us we may not do them simultaneously. Although FOB is relatively benign procedure, the small complication rate and patient discomfort requires calculation of risk against benefit before doing FOB. Hence we tried to evaluate diagnostic yield of these two procedures in patients with hemoptysis with normal chest $\mathrm{x}$ ray.

Literatures suggest that diagnostic yield of CT scan Thorax was usually vary from $17 \%$ to $53 \%$ which include diagnosis like bronchiectesis, tuberculosis, malignancy and pneumonia [5-9]. We had good yield of CT scan Thorax (40\%) in our study with major diagnosis like bronchiectesis and tuberculosis. We had yield of $47 \%$ in FOB which include tuberculosis, bronchitis and bronchogenic carcinoma. In literature diagnostic yield of FOB was varies from 10-23\% with common diagnosis of bronchogenic carcinoma, bronchitis and tuberculosis $[3,8,9]$ which is similar to our study. We have a higher yield in FOB compare to other study and this is because we had picked up a good number of tuberculosis cases (11 cases) in bronchial lavage compared to western literature. This data also reflects high prevalence of tuberculosis in our country compared to western world. Overall we had a diagnosis

International Journal of Medical Research and Review in $46(76.6 \%)$ cases. In $14(23.4 \%)$ cases there was no diagnosis in both the investigation and they were grouped in idiopathic cases .In our study, common diagnosis were bronchiectesis (25\%), PTB (20\%), bronchitis(18.3\%) and bronchogenic carcinoma $(6.7 \%)$ which is similar to other studies[8,10]. Haro et al [10] evaluated 57 patients and in his study common diagnosis were bronchiectasis (25\%), tuberculosis (16\%), lung cancer (12\%), Aspergilloma $(12 \%)$, and bronchitis $(5 \%)$ with overall diagnostic yield of $70 \%$ which is quite similar to our study.

Major function of $\mathrm{FOB}$ in the evaluation of haemoptysis is to exclude bronchogenic carcinoma [11], since early surgical treatment is the only effective treatment. Patients usually have a benign cause and good prognosis after a normal FOB, even if haemoptysis recurs [12]. As is evident from the literature, most cancers found in patients with haemoptysis and a normal CXR are in the central airways[13] and FOB can easily detect them and biopsy can be taken even in their early stage. In most series of such patients who underwent bronchoscopy, the incidence of bronchogenic carcinoma has ranged from $0-16 \%$ [14-21]. In our study, the incidence of bronchogenic carcinoma is $6.7 \%$. Even this low yield, it is useful to know the subgroup at risk, to improve the cost-effectiveness of FOB and eliminate the unnecessary risk. Sood et al[7] analyzed all the studies

Available online at: www.ijmrr.in 60 | P a g e 
published so far and concluded that age above 50, male sex and smokers of 40 pack-years had the highest predictive value for bronchogenic carcinoma In our study, all the bronchogenic carcinoma patients were male and smokers with most of them (75\%) having age $>40$ yrs. So FOB is preferred in patients age more than 40 years with history of smoking.

\section{Conclusion}

For evaluation of hemoptysis with normal chest X-ray $\mathrm{CT}$ and FOB are complementary. FOB have no role in diagnosis of bronchiectesis, whereas bronchitis \& intrabronchial growth like bronchogenic carcinoma and bronchial adenoma were diagnosed in a confirm way (with histological proof) only by FOB. Now the question is which investigation to be done first, FOB or CT. If we do only FOB $39.1 \%$ of total diagnosis would have been missed, whereas if we do CT only we will miss $47.8 \%$ of total diagnosis. Also most of the tuberculosis and all the bronchogenic carcinoma were diagnosed by FOB. These are the diagnoses which require specific treatment. In this regard $\mathrm{FOB}$ has definitely advantage over CT. so in a resource limited country like ours FOB should be the first diagnostic option. However considering the small risk and discomfort with FOB we need to specify subset of patient in who FOB is mandatory. Bronchogenic carcinoma is our main concern as, if it is diagnosed early it may have good prognosis and FOB can only do that. So we may argue that those who have risk of bronchogenic carcinoma, who are male, smokers with age $>40$ yrs, FOB should be done first.

Funding: Nil

Permission from IRB: Yes

Conflicts of interest: The authors report no conflicts of interest

\section{References}

1. Weaver LJ, Solliday N, Cugell DW. Selection of patients with haemoptysis for fiber optic bronchoscopy. Chest. 1979; 76(1):7-10.

2. Poe RH, Israel RH, Marin MG, Ortiz CR, Dale $\mathrm{RC}$, Wahl GW et al. Utility of fibreoptic bronchoscopy in patients with hemoptysis and a nonlocalizing chest roentgenogram. Chest. 1988;93(1):70-5.

3. Haponik EF, Britt EJ, Smith PL, Bleecker ER. Computed chest tomography in the evaluation of haemoptysis . Impact on diagnosis and treatment. Chest 1987; 91(1): 80-5.
4. Weinberger SE. Principles of Pulmonary Medicine. $3^{\text {rd }}$ edition.Philadelphia: Saunders; 1988.

5. Millar AB, Boothroyd AE, Edwards D, Hetzel MR. Role of computed tomography(CT) in the investigation of unexplained haemoptysis. Respir Med 1992;86(1):3944.

6. Magu S, Malhotra R, Gupta KB, Mishra DS. Role of computed tomography in patients with haemoptysis and a normal chest skiagram. Indian J Chest Dis Allied Sci. 2000 Apr-June;42(2):101-4.

7. Sood R, Mukhopadhyaya S. Approach to a patient with haemoptysis and a normal chest X-ray. J Indian Acad Clin Med. 2002;3(1):14-22.

8. Jones R, Latinovic R, Charlton J, Gulliford MC. Alarm symptoms in early diagnosis of cancer in primary care: cohort study using General Practice Research Database.

BMJ.2007;334(7602):1040.doi:10.1136/bmj.39171. 637106.

9. Haro Estarriol M, Vizcaya Sanchez M, Jimenez Lopez J,Tornero Molina A. Etiology of hemoptysis: prospective analysis of 752 cases. Rev ClinEsp 2001;201(12):696-700.

10. Haro M, Jiménez J, Tornero A, Vizcaya M, Tirado $\mathrm{R}$, Cros T. Usefulness of computerized tomography and bronchoscopy in patients with hemoptysis. Analysis of 482 cases.An Med Interna 2002;19(2):59-65.

11. Barrett RJ, Tuttle WM. A study of essential haemoptysis J Thorac Cardiovasc Surg. 1960 Oct;40:468-74.

12. Snider GL. When not to use bronchoscope for haemoptysis (Editorial). Chest. 1979 Jul;76(1):1-2.

13. Zavala DC. Diagnostic fiberoptic bronchoscopy: techniques and results of biopsy in 600 patients. Chest. 1975 Jul;68(1):12-9.

14. Jindal SK, Gilhorta R, Behera D. Fiberoptic examination in patients with hemoptysis and normal chest X-ray. J Assoc Physicians India. 1990 Aug;38(8):548-9.

15. Sharma SK, Dey AB, Pande JN, Verma K. Fiberoptic bronchoscopy in patients with haemoptysis

Available online at: www.ijmrr.in 61 | P a g e 
Research Article

and normal chest roentgenograms. Indian $\mathrm{J}$ Chest Dis Allied Sci. 1991 Jan-Mar;33(1):15-8.

16. Suri JC, Goel A, Singla R. Cryptogenic haemoptysis: Role of fiberoptic bronchoscopy. Indian J Chest Dis Allied Sci. 1990 Jul-Sep;32(3):149-52.

17. Jackson CV, Savage PJ, Quinn DL. Role of fiberoptic bronchoscopy in patients with haemoptysis and a normal chest roentgenogram. Chest. 1985 Feb;87(2):142-4.

18. Lederle FA, Nichol KL, Parenti CM. Bronchoscopy to evaluate haemoptysis in older men with non- suspicious chest roentgenograms. Chest. 1989 May;95(5):1043-7.

19. Zavala DC. Diagnostic fiberoptic bronchoscopy: techniques and results of biopsy in 600 patients. Chest. 1975 Jul;68(1):12-9.

20. Heimer D, Bar-Ziv J, Scharf SM. Fiberoptic bronchoscopy in patient with haemoptysis and nonlocalizing chest roentgenogram. Arch Intern Med. 1985 Aug;145(8):1427-8.

21. Heaton RW. Should patients with haemoptysis and a normal chest $\mathrm{x}$ ray be bronchoscoped? Postgrad Med J. 1987 Nov;63(745):947-9.

\section{How to cite this article?}

Agarwala A, Basuthakur S, Shamim S, Saha K, Bhattacharya S, Sengupta A. Diagnostic Yield of Fiber Optic Bronchoscopy and CECT Thorax in Patients of Haemoptysis with Normal Chest X-Ray. Int J Med Res Rev 2015;3(1):5762. doi: 10.17511/ijmrr.2015.i1.10 